LBL- -20329

DE86 002892

\title{
OPTIMIZATION OF THE PARAMETERS OF A STORAGE RING FOR A HIGH POWER XUV FREE ELECTRON LASER*
}

A. Jackson, J. Bisognano, S. Chattopadhyay, M. Cornacchia, A. Garren, K. Halbach, K. J. Kim, H. Lancaster, J. Peterson, M. S. Zisman

\author{
Lawrence Berkeley Laboratory \\ University of California \\ Berkeley, California 94720
}

\author{
C. Pellegrini, G. Vignola \\ Brookhaven National Laboratory \\ Upton, L.I., New York 11973
}

\section{DISCLAIMER}

\begin{abstract}
This report was prepared as an account of work sponsored by an agency of the United States Government. Neither the United States Government nor any agency thereof, nor any of their employees, makes any warranty, express or implied, or assumes any legal liability or responsibility for the accuracy, completeness, or usefulness of any information, apparatus, product, or process disclosed, or represents that its use would not infringe privately owned rights. Reference herein to any specific commercial product, process, or service by trade name, trademark. manufacturer, or otherwise does not necessarily constitute or imply its endorsement, recommendation, or favoring by the United States Government or any agency thereof. The views and opinions of authors expressed herein do not necessarily state or reflect those of the United States Government or any agency thereof.
\end{abstract}

* This work was supported by the Director, Office of Energy Research, Office of High Energy and Nuclear Physics, High Energy Physics Division, U.S. Dept. of Energy, under Contract No. DE-AC03-76SF00098 and, in part, under Brookhaven National Laboratory DOE Contract No. DE-AC02-76CH00016. 
This report was done with support from the Department of Energy. Any conclurions or opinions expressed in this report represent rolely those of the author(s) and not necessarily those of The Regents of the Uaiversity of Califorain, the Lawrence Berkeky Leboratory or the Department of Enercy.

Reference to a company or product anme does not imply approval or recommendation of the product by the University of Californil or the U.S. Department of Energy to the exclusion of others that may be suiuble. 
Optlmization of the Parameters of a Storage Rling for a High Power XuV Free Electron Laser

A. Jackson, J. Bisognano, S. Chattopadhyay, M. Cornacchia, A. Garcen. K. Halbach. K.J. Kim, H. Lancaster, J. Peterson, M. S. Zisman

\author{
Lawrence Berkeley Laboratory \\ \#1 Cyclotron Rd. MS 47-112 \\ Berkeley, Cal1Eornta 94720 \\ C. Pellegrinl, G. Vignola \\ Brookhaven National Laboratory \\ Upton, L.I., New York 11973
}

\begin{abstract}
In this paper we describe the operation of an XUV high gain FEL operating within a bypass of an electron storage ring, and discuss the implications on storage ring optimization 1mposed by FEL requirements. It transpires that, in the parameter reglme of interest, collectire effects within the bean play an important role. For example, intrabeam scattering dliutes the transverse emittance of the beam and the microwave Instability Increases the momentum spread. Both phenomena reduce the effectiveness of the FEL. A computer code, ZAP, has been written which, for a given lattice design, takes all such effects Into consideration and produces a figure of merit for EEL operation for that nachine. We show the results of ZAP for several storage ring destgns, all optimlzed for FEL operation, and present a design example of a facility capable of producing coherent radiation at $400 \mathrm{~A}$ wth tens of megawatts of peak power.
\end{abstract}

\title{
1. Introduction
}

There has recently been remarkable progress in demonstrating the generation of coherent radiation through Eree Electron Laser (EEL) interaction in the infrared end microwave region (Ref. 1). With electron beams of suitable quality, the technique could be extended to wavelengths shorter than $1000 \mathrm{~A}$.

With present day technology, there are two promising approaches to the vacuum ultraviolet (XUV) EEL. One is based on cavity formation by end mirrors (Refs. 2 and 3 ). the other through the development of high gain in a single pass device. The former "fEL oscillator" is currently restricted to longer wavelengths because high reflectivity mircors (alchough rapidly evolving through multilayer technology) are not yet avatlable (Ref. 2). In the second approach, which we call the High Gain FEL, the interaction between the electron beam and the undulator occurs in a single pass, and no mirrors are required.

The most promising source of electrons with the characteristics required for FEL operation is an electron storage ring. The mode of operation is to deflect the circulating electron bunch Into a special bypass containing the FEL undulator, as shown schematically in Figure 1. The beam, which is severely disrupted in the FEL interaction 1s then reinjected into the storage ring. Where its equilibrium characteristics are restored through the process of cadiation damping. After one damping time (50-100 ms), the beam is ready to be switched back into the FEL bypass and the process is repeated. References 4 and 5 give a more detalled description of EEL bypass operation.

In this paper we show how the evolution of the optical pulse in the FEL is determined by certaln characterlstics of the electron pulse, in particular, the charge denstty and momentum spread. We show how these requirements lead to conflicting demands on the storage ring design, and how these conflicts have been assessed in a systematic fashion through the development of a new computer code. ZAP.

This novel. systematic approach has been used to choose between candidate storage rirg lactices, all of which were opcimized for high gain FEL operation. Based on our study ar present a design example that is capable of producing coherent radiation at 400 a with rens of megawatts peak power. 


\section{EEL ISSUES}

EEL Gain, Power, Saturation Lengch

An electron beam of energy $y m_{e} c^{2}$ teaveling through a magnetic undulator of period $\lambda$. can Interchange energy with a $t$ kansverse laser Eield of wavelength $\lambda$ propagating in the same direction (Refs. 6 and 7 ). The interaction becomes cesonant when the following condlition is satisfied:

$$
\lambda=\frac{\left(1+k^{2} / 2\right)}{2 r^{2}} \lambda_{u}
$$

whera $K$ is the deflection parameter, characteristic of the undulator, given by

$$
K=\frac{e \lambda_{4} B}{2 \pi L_{0} C}=0.934 \lambda_{\left.L_{[C X}\right]}^{B}[\text { Tes la] . }
$$

An 1oportant quanticy, which determires the FEL characteristics in the one-dimenstonal theory, is the dimensionless parameter $p$, given by (Ref. 8 )

$$
\rho=\left(\frac{\mathrm{K}^{2}[\mathrm{JJ}] \Sigma_{\mathrm{e}} m_{\mathrm{b}} \lambda_{u}^{2}}{32 \pi \gamma^{3}}\right)^{1 / 3}
$$

where

$$
[J J]=\left[J_{0}(E)-J_{1}(E)\right]^{2} \text { wich } E=\frac{k^{2}}{4\left(1+k^{2} / 2\right)} .
$$

The $J_{\text {f }}$ and $J_{1}$ are ordinary Bessel functions $\mathrm{ff}$ order zero and one, respectively. As wil em8rge In the course of this paper, for the paramerers of interest to us, $p$ is typically of the order of $10^{-3}$.

The characteristics of the power growth of the laser wave, as obtained from the one-dimensional theory, fall into three distinct regimes: the small-signal regime, the exponential-growth regime and the sacuration regime. Near the entrance of the undulator, where the small-signal theory applies, the gain $G$ (defined as the ratio of the laser power at two polnts separated by a distance $z$ along the undulator axis) is given by

$$
G=536\left(\rho 2 / \lambda_{u}\right)^{3}
$$

Farther along the undulator, the laser power P grows exponentially (Refs. 9 to 14) wlth distance, Erom the intelal power $P_{0}$ at a rate proportional to:

$$
P=\frac{P_{o} e^{g z}}{9}
$$

where

$$
8=4 \pi \sqrt{3}\left(p / \lambda_{U}\right)
$$

The corresponding e-folding length for the growth of the radiation power in the exponential growth regime is

$$
R_{e}=8^{-1}=\frac{1}{4 \pi \sqrt{3}} \frac{\lambda_{\mathrm{U}}}{\rho} .
$$

Esencually, the electrons are captured in the pondecomotive potential well and the zeowth of cadtation power scops. The laser saturates at a distance $z=z$ wish $a$ -atactertstle sacurated peak po'der Psat. The saturation length and the \$alk power dre 3:Jen aporoxiately by (Ref. 8) 


$$
\begin{aligned}
& z_{\text {sat }}=\left(\lambda_{\mathrm{U}} / \rho\right) \\
& \mathrm{P}_{\text {sat }} \approx \rho \mathrm{P}_{\text {beam }}
\end{aligned}
$$

where $\mathrm{P}_{\text {beam }}=\hat{\mathrm{I}} \mathrm{E} / \mathrm{e}$ is the peak power in the electron beam. The optinum itice for the number of undulator perlods $N$ is glven by

$$
N=\left(z_{s a t} / \lambda_{u}\right)=(l / \Delta)
$$

This chotce for the number of undulator perlods maximizes the laser power in the shortest posstble undulator length.

Taking the typical values of $\hat{I}=200 \mathrm{~A}, \mathrm{E}=750 \mathrm{MeV}$ and $p=1 \times 10^{-3}$ considered in this paper, one obtains from Eqn. (2.10) a peak laser power of ljo MW. Assuming a beam pulse length of 100 psec and a repetition time (equal to the typical longltudinal damping time of the storage $[\mathrm{ing}$ ) of $50 \mathrm{msec}$, we obtain an average power of 0.3 watts.

A coherent source of radiation of such high intensity, both in peak and average power, would certainly ploneer novel scientific applications.

\section{Relationsh1ig Between Laser Power and Electron Beam Parameters}

We have seen that the FEL parameter $\rho$ determines the peak power that can be obtained from the laser. In what follows, we try to relate this parameter to the electron beam and storage ring chacacteristics.

The volume density of the bunched electron beam is

$$
n_{b}=\frac{i}{\cos 2 \pi \sigma_{x} \sigma_{y}}
$$

The beam size $\sigma_{x, y}$ can be expressed in terms of the emittances $c_{x, y}$ and the amplitude
unctions $b_{x, y}:$

$$
\sigma_{x, y}=\sqrt{c_{x, y} \beta_{x, y}}
$$

The alternating fleld of an undulator provides an effective focussing force. For a planar undulator, the focussing is in the vertical direction, with an effective B-Function given by (Ref. 15)

$$
B_{y}=\frac{\lambda_{u} Y}{\sqrt{2} K \pi}
$$

Horizontal focussing can also be provided by tilting or by shaping the pole surfaces of the undulator (Ref. 16). In elther case, the focussing strength in the vertical plane is thereby reduced. For the purpose of concepcual simplicity, we assume a focussing force of the same magnitude in both directions:

$$
B_{x}=B_{y}=\frac{\lambda_{u} Y}{K \pi}
$$

By combining Eqns. (2.1), i2.12), (2.13), and (2.15), the EEL parameter given in Eqn. (2.3) can be ceuritten:

$$
\rho^{3}=\frac{1}{16 \pi} \frac{r_{\text {e }}}{\text { ec }} \frac{K^{3}[J J]}{2\left(1+K^{2} / 2\right)} \frac{\lambda}{r^{2}} \frac{\bar{I}}{\sqrt{2 \cdot x^{c} y}}
$$

The above cesults apply only to the one-dimensional theory with zeco energy spread. LE 3 Einite energy spread is taken inco account, the growth rate and the saturation power 3 re modified as follows (Ref. 17 ):

$$
\begin{aligned}
& \mathrm{g} \rightarrow \mathrm{B}^{\prime}=\mathrm{E}\left(\sigma_{\mathrm{P}}, \rho\right) \mathrm{g} \\
& \mathrm{P}_{\text {sat }} \mathrm{P}_{\text {sat }}=h\left(\sigma_{p}, p\right) \mathrm{P}_{\text {sat }}
\end{aligned}
$$


The $E\left(\sigma_{p}, \rho\right)$ and $h\left(\sigma_{p}, \rho\right)$ are Eunctions of the electron relative energy spread, $a_{p}=(\Delta p / p) r m s$, and $\rho$, and describe form Eactors that, in general, decrease with increasing values of $\left(\sigma_{p} / \rho\right)$. If $\sigma_{p}$ is non-zero, the FEL performance is sigiticicantly reduced unless the Eoliowing condition is satisfied (Ref. 18):

$$
\sigma_{p} \leq L / N-\rho
$$

If the momentum spread of the electron beam is large and the inequality in Eqn. ( 2.18 ) is violated, both Eunctions $f$ and $g$ can become considerably less than unity, thus degradtng the EEL performance. The function $E(a, p)$ can be obtalned by solving a dispersion relation, which becomes a cublc equation fBr a Lorentzian or a rectangular longltudinal momentum distribution. For a Lorentzian distribution, the value of $f\left(\sigma_{p}, p\right)$ is 1 when $\sigma_{p} / p=0$ and 0.36 when $\sigma_{p} / p=1$.

In addition to the natural energy spread, the beam emittance contributes an effective energy spread (Ref. 5) that is subject to a condition similat to Eqn. (2.18). Making use of Eqn. (2.15) and under the assumption that the transverse charge distributions are Gausstan, the effective energy spread can be written:

$$
\left(\sigma_{p}\right)_{\text {eEE }}=\frac{\sqrt{\left(c_{x}^{2}+5 c_{y}^{2}\right)} k_{\pi}}{2 \sqrt{2} \gamma \lambda}
$$

For all the cases consldered in thls paper, the effective energy spread is not negligible, but is usualiy smaller than the natural $\sigma_{p}$.

In deteraining a "Elgure of mertt" for a glven storage ting by which it way be compared Wth others, we atcenpt to achieve the maximum peak power output in the shortest undulator length for a glven output wavelength. We see from equations (2.6) and ( 2.8 ) that this cequires maximizing the gain parameter, $p$. In termg of the storage ring design, we see that maximlzing $p$ involves maximlzing the value of $\left[/\left(y^{2} \sqrt{c_{x} c_{y}}\right), 1 . e .\right.$, maximizing the curtent densiey, In the next section we discuss the problems of achieving high density electron bunches in a storage clng.

\section{Problems in Achleving Htah Density Electron Bunches and The le Implicat lons for storage Rtng Design}

In this section we review the collective effects that lintt the alectron density achlevable In a storage ting and show how they demand conflicting requlrements from the ring design

The interaction of the beam with les enviconment produces electromegnetic flelds which react back on the bead. This feedback mechanism causes a variety of coherent lnstabili. ties to develop that elther cause the momencum spread to Increase of limit the maximum achterable current. Elther effect is deleterious to FEL performance.

For the fEL cings we have considered, the longleudinal ulcrowave instability presents the most severe limitation. Here the threshold peak curcent is 81 en by (Ref. 19 ):

$$
\hat{I}_{L} \cdot \frac{2 \pi \sigma_{p}{ }^{2}(E / \theta)}{\left(\tau_{L} / n\right)_{e f E}} F_{L}
$$

where $E_{\text {is }}$ is the longitudinal form factor ( $a l$ ) and $(z / n)$ is the effective longltudinal tmpedance, which is the average of the full Erequencf dependent impedance over the bunch mode spectrum.

Already we can see conflicting cequicements. Fron equacion (2.18) we wish to keep of snall, whlch Erom equation ( 3.1 ) lowers the peak current achievable. This could be oflse by designing a lactice with a large momentum compaction factor, a. However, increasing I demands a larger tf voltage to natntain the momentum acceptance of the storage $t$ ing which in general whl cesult in more cf cavities and chereby nore longltudinal iapedanc-

Thls aspect of parameter optimization is furcher exacerbaced by che cequicements of another effect. Intrabeam scattering. In this process electrons within the bunch cou scacter off each other cransfering energy predominancly from cransverse inco longitudi notion. When such a scatcer occurs in a dispersive region of the lactice, a radial betacton osclilation is exciced. The net resulc is that the beam grows both cadially. longltudinally, thereby increasing che emitcance and diluting the bunch densicy. 
Quantitatively, the treatment of intrabeam scattering is quite complicated (Ref. 20 ). hoinever, For the type of lattices under consideration, an approni ale expression for the radial diffusion rate was found to be:

$$
\begin{aligned}
& \frac{1}{\tau_{x}}=c \frac{\hat{L}}{c_{x}{ }^{2}}\left\langle\frac{\sqrt{H}}{\sigma_{p} r^{3} \sqrt{\beta_{y}}}\right\rangle \\
& H=r_{x} \eta^{2}+2 a_{x} \eta \eta^{\prime}+\beta_{x} \eta^{\prime 2}
\end{aligned}
$$

with $\alpha_{x}, \beta_{x}$ and $\gamma_{x}$ being the lattice Twiss parameters, $\eta$ the dispersion function and $\eta^{\prime}$ its derivative.

It is immediately seen that all the requirements for the high gain FEL tend to increase the diffusion rate. Horeover, buried in $H$ is a requirement to reduce she dispersion in the lattice and so reduce $a$, in direct conflict with the requirement on a from the longitudinel miccowave instability.

Large angle Coulomb scattering results in a longltudinal (momentum) excursion which can

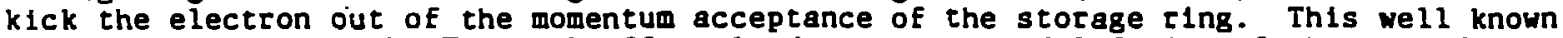
phenomenon known as the Touschek effect leads to a reduced lifetime of the stored electron beam. The Touschek lifetime is proportional to the cube of the energy $\left(\gamma^{3}\right)$, the square of the morantum acceptance, and inversely to the beam density. Thus, increasing the Touschek lifetime moves in the direction of reducing the FEL gain, $\rho$.

By now it should be apparent that there is little chance of finding a prescription by which storage ring parameters can be found to simultanenusly satisfy the various constraints. What is required is a way in which to judge the sultability of a given lattice for a given application, in this case, the XUV-FEL. To this end we have begun the development of a new computer code called ZAP.

In broad outline, the program works as follows. As primary inputs, ZAP ut1l1zes the parameters of a lattice (betatron functions, dispersion, momentum compaction, natural emittance, radiation damping time) along with the relevant "physics" needs (e.8., the FEL requirement for small momentum spread). The code then calculates, as a function of the rms bunch length, the required $r F$ voltage and the corresponding bucket helght. Inpedance estimates are made and, based on these, calculations of the longltudinal and trensverse threshold currents. From the lower of these threshold current values and the radiation damping time, ZAP calculates the intrabeam scattering (IBS) rates and 1 terates to find the equilibrium transverse and longitudinal emittances (where the IBS and the quantum exc1tation are balanced by the radiation damping). Finaliy, the equilibrium emittance values and $a$ selected momentum acceptance are used to obtain the Touschek iffetime of the ring. Other options of the code include calculation of the primary Fel parameters, gas scattering lifetime, and estiaates of multibunch instability growth rates and frequency shifts.

Thus, from the earliest stages of a lattice design, ZAP can be used to Indicate whether or not the design is worth pursuing and, if so, in which directions improvements could be made. Detalls of the way in whtch the code works can be found in Ref. 22.

A good example of the use of zAP is the determination of parameter variation with the

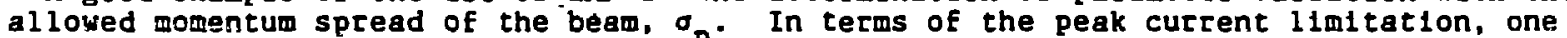
of the ways of gaining (as can be seen ${ }^{p}$ in Eqn. (3.1)) is to increase the allowable momentum spread of the beam. For low values of $\sigma_{p}$. we expect the peak current to increase as of. At larger values of $\sigma_{p}$ this increase flattens out, because the lmpedance becomes $I F$ dominated, and thus the impedance is also increasing quadraticaliy with $\sigma_{p}$. (In this latter regime the longltudinal threshold is no longer dominant anyway.) Below op of about 0.005 , the peak current limitation arises Erom the longitudinal threshold. whereas above this value the transverse threshold would dominate. Obviously the peak curcent performance improves with tncreasing momentud spread. Unfortunately, the gain of an FEL degrades rapidly if $\sigma_{p}$ is greater than the p parameter. This degradation of FEL performance with increasing momentum spread is illustrated in Eig. 2 , which shows the increase in e-Folding length (leff) and decrease in gain parameter (peff) compared with their zero-energy-spread values $\left(\ell_{e}, p\right)$. For the designs considered here, we conclude that the value of $\sigma_{p}$ that can be achieved in the storage ring (as a compromise between storage rinp, and EEL pertormance) is about 0.002 . 


\section{Tine Goherent XUV Eacilicy (CXF)}

For the parametric studies of the lactices considered for th? CXE, some cominon assumption were made. Eor example. impedance estimates Eor cire cing include the "SptiAR coll-off" when bunch lengchs are shocter than the average beam pipe cadius. Included in

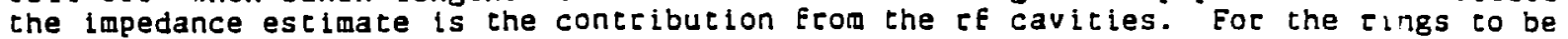
discussed in this paper, we standardized on the $500 \mathrm{MHz}$ cF cavity used in PETRA. The requiced number of cf cells is estlmated (assuming a peak tf volicage of 509 ':V/cell) based on the voltage needed to maincain a befin of the chosen momentum spread and bunch length within the linear part of the rf acceptance. (This estimate leads to a minimum $r F$ tequirement, which is priferted for both economic and impedance reasons.) Based on measurements of the PETRA cavities (Ref. 21), we have assumed a contribution to the longitudinal broadband Impedance of $3.66 / R$ ohms/cell and a transverse contribution per cell of 4,000 ohms/m.

Five different lattices of three types were 1nvestigated for the CXF. Detalls of the lateices and a discussion of how their parameters ovolved can be found in Ref. 22 .

In each case, the visbility of the lattice (tunability, chromatic behaviour, dynamic aperture, atc.) has been confirmed, and the parameters optimized to give the best performance in terms of a CXE. A sumary of each lattice, and the cesults of the analysis using ZAP, are presentod 1:1 Tables 1 and 2 , respectively.

Table 1. Summary of Lattice Parameters

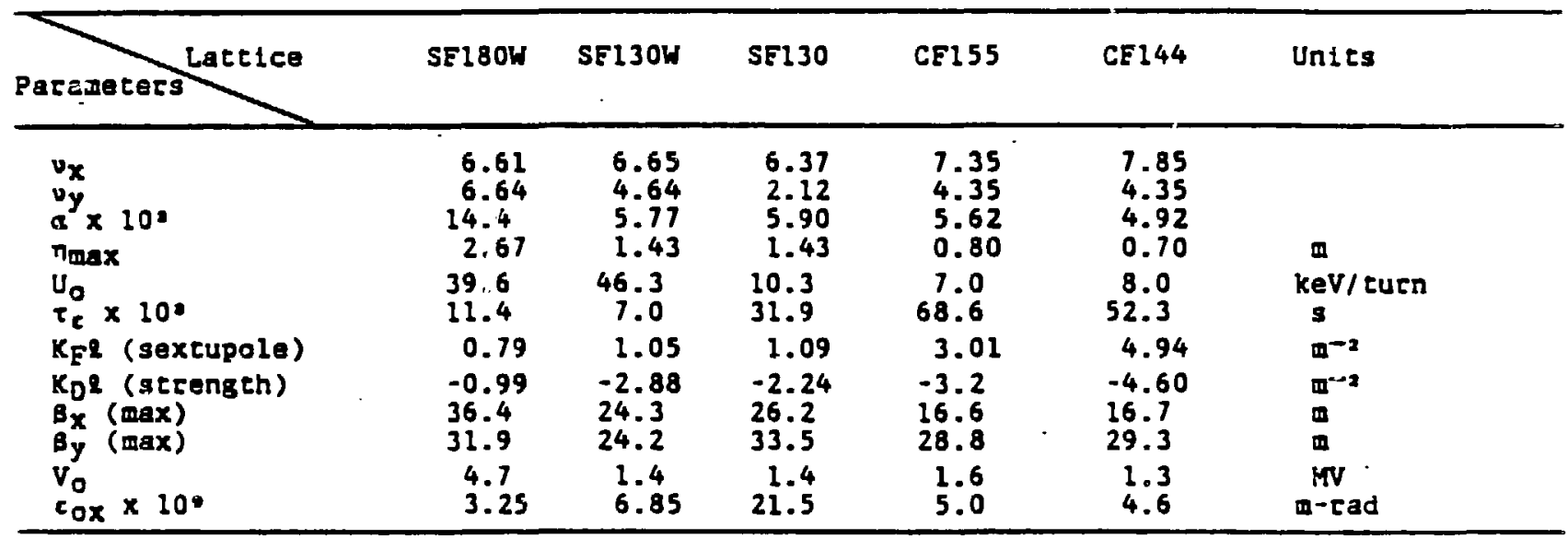

Table 2. Parameters Predteted by ZAP

\begin{tabular}{|c|c|c|c|c|c|}
\hline Lattice & SElBuí & SE130W SE130 & CEI5S & CE144 & Units \\
\hline
\end{tabular}

\begin{tabular}{|c|c|c|c|c|c|c|c|}
\hline$\tau_{\times} \times 10^{\circ}$ & $10: 1$ & 10.2 & 7.4 & 24.8 & 12.9 & 10.1 & a-cad \\
\hline$?^{x}$ & & $\begin{array}{l}376 \\
0.0125\end{array}$ & $\stackrel{123}{0.0125}$ & $\begin{array}{l}230 \\
0.0125\end{array}$ & $\begin{array}{r}214 \\
0.0125\end{array}$ & $\begin{array}{l}199 \\
0.0125\end{array}$ & $\begin{array}{l}\mathbf{A} \\
\mathbf{0}\end{array}$ \\
\hline$\tau_{F}$ & $10: 1$ & 1.0 & 2.4 & 3.7. & 2.0 & 1.4 & h \\
\hline$\frac{\hat{\imath}}{\sqrt{x^{2} y}} \times 10-10$ & $\left\{\begin{array}{r}1: 1 \\
10: 1 \\
100: 1\end{array}\right.$ & $\begin{array}{r}9.4 \\
11.6 \\
19.2\end{array}$ & $\begin{array}{r}3.3 \\
5.3 \\
11.8\end{array}$ & $\begin{array}{l}1.8 \\
2.9 \\
7.2\end{array}$ & $\begin{array}{l}4.2 \\
5.2 \\
8.7\end{array}$ & $\left.\begin{array}{r}5.0 \\
6.2 \\
10.5\end{array}\right\}$ & $A \mathbb{m}^{-1}$ \\
\hline$D \times 10^{3}$ & $10: 1$ & 1.6 & 1.3 & 1.0 & 1.3 & 1.3 & \\
\hline
\end{tabular}

Solely in terns of the EEL gain parameter, o, the lattice SEl80w (a Chasman-Green structure with hlgh fleld whglec Insections to lapcove the synchrotron damping rates) has the best Elgure of nerti. However, tc has not been chosen as the preferted solution amongst ocher latcice optlons. It is perhaps worthwhile to summarize here what seemed to us to be the drawbacks of thls latclce. 
- The operation of a storage ring with a relatively large proportion of its circumference occupied by high field wiggler magnets like SElBOW may present problems, or at least introduces an elemenc of uncertainty in the beam dynamics aspects of the storage ring. The non-linear effects of high field wiggiers on the long term stability of the beam are not yet known, and nore cheoretical and experimental work is needed.

Eree space for conventional undulators has been reserved in the lattice. [t is beyond the scope of this paper co discuss che detailed aspects of the machine operating in the more conventional undulator mode. These undulacors would probably operate at different beam energies from the EEL. Different optics solutions would be needed for the two modes of operation (FEL operation at low energy and conventional undulator operation at the peak energy of $1.3 \mathrm{GeV}$ ).

- The large energy acceptance (3\%) needed for an acceptable Touschek lifetime requires powerful ff system (4.7 MV peak voltage at $750 \mathrm{MeV}$ compared with $1.3 \mathrm{MV}$ Eor lattice CE144, For example).

Large dynamic and phystcal apertures are required to accept an electron that experiences a momentum change of $3 \%$ due to Coulomb scattering within the achromat, where the peak dispersion is $2.7 \mathrm{~m}$.

- It was found that the chromatic properties of this lattice are very sensitive to the exact location of the chromaticity sextupoles.

The lattices designated "CF" are Vignola-cype combined function lattices (Ref. 23), which give emittance values comparable to those of the separated function lattices having wigglers. Moreover, they have the operational simplicity that a lattice with wigglers does not have, e.g., easy energy varlability and excellent chromatic properties. Although there is some penalty in FEL performance, the siaplicity and relative cost-effectiveness of this type of lattice make it appear a good candidate for further study. For these reasons, we have adopted the lattice CF1 44 as our cholce for presentation as ihe destgn example for the CXF.

A detalled discussion of lattice CF144 can be found in Ref. 22, together with a description of some of the necessary facility subsystems (injector, re, bypass, and undulator). Here we present for completeness a layout drawing of the factitty, Figure 3 , and the lattice functions through one of the (six) unit cells, Figure 4.

With the parameters outlined in Table 2, 1.e., $\hat{I}=199 \mathrm{~A}$ at $750 \mathrm{MeV}, \sigma_{\mathrm{p}}=2 \times 10^{-3}$ and $p=1.3 \times 10^{-3}$, we obtain an effective gain parameter of peff $=0.2 \times 10^{-3}$ (see F1gure 2 ). which gives a peak power in the optical pulse of $-30 \mathrm{MW}$.

The FEL bypass system which complements CF144 has also been des1gned. The layout of the extraction eleniezts leading to the FEL undulator is shown in Flgure 5 , and the matchea optical functions along this section of the bypass are given in Figure 6 . Reinjection tnto the storage ring from the bypass is a mircor laage of the extraction side.

Finally, let us consider the EEL undulator itself. It is seen Erom Eqn. (2.16) that a high value of the deflection paraweter $K$ is desirabie. As $K$ ranges from 0 to infinity in Eqn. (2.4), the argument $E$ of the Bessel functions in [JJ] ranges only $E$ rom 0 to 0.5 ; thus, [JJ] becomes constant as $K$ increases. For large $K, \rho^{3}$ is simply proportional to $K$. For Flxed $\lambda$ and $Y, a$ higher $K$ demands a smaller undulator period $\lambda_{u}$ in order to satisfy the resonant condition (see Eqn. (2.1)). Note that this 1s consistent with the demand for a smaller saturation length ( $\left.z_{\text {sat }}=\dot{\lambda}_{u} / \rho\right)$.

From Eqn. (2.2) we see that if one wants a smaller undulator perlod without reducing $K$, the undulator fleld $B$ must increase. This requires reducing the undulator gap. We use the Following approximate empirical relation for the field of a hybrid undulator having a steel-permanent-magnet (samarlum-cobalt, Ref. 24) design:

$$
B[\operatorname{tes} l a]=3.34 \exp \left\{-\frac{d}{\kappa_{u}}\left[5.47-1.8 \frac{d}{\kappa_{u}}\right]\right\}
$$

Where $d$ is the undulator gap.

In practice, the deflection parameter $K$ cannot be increased too much, or else the effective energy spread in Eqn. (2.19) becomes significant and degrades the FF.L performance. Even with this coristraint, the undulator gap is scill sall enough co signiflcancly discupt the beam. tris requiring a bypass for the EF.L (Ref. 22). The undulator parameters of interest in our design ace summarized in Table 3 . 


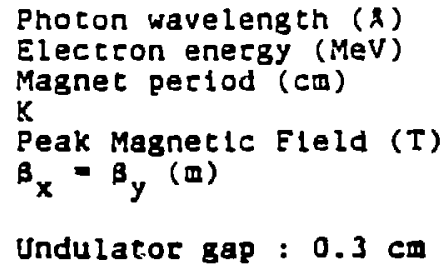

Undulator gap : $0.3 \mathrm{~cm}$

\begin{tabular}{ll}
\hline 500 & 400 \\
1.85 & 150 \\
2.50 & 2.29 \\
1.45 & 3.61 \\
2.31 & 1.67
\end{tabular}

\begin{tabular}{|c|c|}
\hline $\begin{array}{l}500 \\
2.36 \\
3.77 \\
1.71 \\
1.95\end{array}$ & $\begin{array}{l}750 \\
2.91 \\
5.26 \\
1.93 \\
2.59\end{array}$ \\
\hline
\end{tabular}

\section{Summary and Conclusions}

We have shown thet in a single pass, high gain EnL driven by an electron storage 5 ing, the ulctwate performance of the EEL is Intrinstcally tied to the electron beam parameters. It 13 demonstrated that high charge denstties are required and that, in such a reglme, collective effects dominate the equilibrium behaviour of the stored beam. In order to Identify the parameter dependencs, we have written a new computer program, called ZAP. Which has been used to select and optinlize a particular storage ring lattice structure for use in an XUV coherent radiation facility. The viability of such a faclitty has been confirmed and we predict an output power of -30 MW peak, at a repet1tion rate of $-20 \mathrm{~Hz}$.

\section{Acknowledgment}

Th1s work was supported by the Director, Offlce of Energy Research, Offlce of HIgh Energy and Nuclear Physics. High Energy Physics Division. U.S. Dept. of Energy, under Contract No. DE-AC03-76SE00098.

\section{References}

1. See the contributed papers to the Castelgandolfo 1984 FEL Conference, Nucl. Inst. and Methods in Physics Research, to be published (1985).

2. D.I. Attwood et al.. In Eree Electron Generation of Extzeme Ultraviolet Coherent Radiation, J.M.J. Madey and C. Pellegrin1, eds., Amer. Inst. Phys., New York, 1984, (Cons. Proc. No. 118), p.294.

3. C. Pellegrini, Nucl. Inst. Meth., 177. 227 (1980).

4. An experiment on the HIgh Gain EEL In the microwave range was carcled out by a Lawrence Berkeley Laboratory/Lawrence LIVergort National Laboratory Group. W.B. Colson and A.M. Sessler. "Eree Electron Lasers", LBL-18905 (January 1985), subaltted to Annual Reviews of Nuclear and Particle Sclence. T.J. Orzechowsk1, et al., UCRL-91559 (September 1984), submitced to Phys. Rev. Lett.

5. J. Murphy and C. Pellegrinl, Intl. Quant. Elec. Conf., Paper hQQ2, San Diego, CA (June 1984).

6. For a review, see for example, H.B. Colson, Phystes of Quantum Electronics, 8 (EEL Generation of Coherent Radlation, S.F. Jacobs et al. eds., Addison-Wesley, lS82), $p$. 457 .

7. J. M. J. Madey, J. Appl. Phys.. 42. 2906 (1971); and J. M. J. Madey, M. A. Schwettran, H. M. Fal.bank, IEEE Trans. Nucl. Sci., NS-20, 980 (1973).

8. B. Bonlfaclo, C. Pellegrinl and N. Narduccl. In Eree Electron Generation of Extreme Ultcaviolet Coherent Radlation, J.M.J. Madey and C. Pellegrint, eds. (Aner. [nst. Phys., New Yock, (984), p. 236.

9. N.M. Kooll and 'A.A. Mc.Yullin. Phys. Rev., All, 300 (1978).

10. A. Gover and Z. Livnl. Opt. Conm., 26. 315 (19/8).

1L. I.3. Becnscein and J.L. Hleshfeld, Phys. Rev.. A2.Q. 160l (1979). 
12. P. Sprangle, C.M. Tang and W.M. Manheimer, Phys. Rev.. A2l, 302 (1980).

13. C.C. Shih and A. Yariv, LEEE J. Quant. Electron.., QE-17, 1387 (1981).

14. G. Dattol1. A. Marino, A. Reniecl and E. Romanelli, IEEE J. Quant. Electron., QE-li, $1371(1981)$.

15. Calculations by. For Instance, K. Halbach. See also Ref. I7.

16. E.T. Scharlemann, Lawrence Livermore National Laboratory, ELE Note 105 (July 1984).

17. K. J. Kim and J. M. Peterson, "Storage RIng Parameters for High Gain FEL," Lawrence Berkeley Laboratory, Paper presented at the 1985 Particle Accelerator Conference. Vancouver, BC, Canada, May 13-16, 1985.

18. J. Murpt;, C. Pellegrini, B. Bonifacio, Optics Commun zations, 53, 197 (1985).

19. For a review, see, for instance, C. Pellegrinl, Brookhaven National Laboratory Report 51538 (April 1982), and J.L. Laclare; XIth Intl. Conf. on High Energy Accelerators, Geneva (1980), P.526.

20. J.D. Bjorien and S.E. Mtingwa, Particle Accelerators, 13,115 (1983).

21. T. Weiland, DESY Report 83-005, February, 1983.

22. J. Blsognano, et al., "Feasibility Study of a Storage Ring for a High Power XuV Eree Electron Laser," (LBL-19771, June, 1985), to be published in Particle Accelerators.

23. G. Vignola, "Preliminary Design of a Dedicated $6 \mathrm{GeV}$ Synchrotron Radiation Storage Ring", Submitted to Nucl. Inst. Meth.

24. K. Halbach, Journal de Physique Colloque, Cl, 44, 211 (1983). 


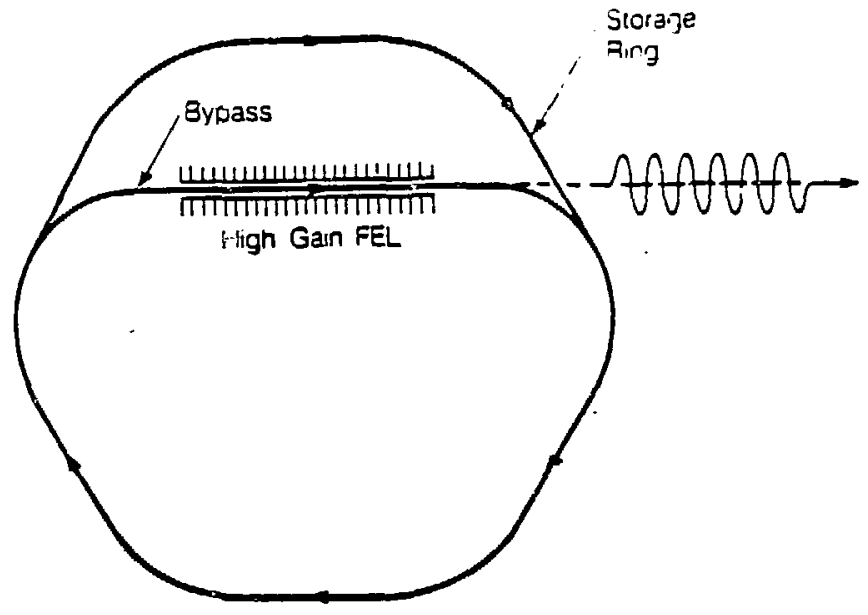

E1g. 1 Schematic drawing of a storage ring with a bypass contalning a high gain EEL.

$x B L+85+10171$

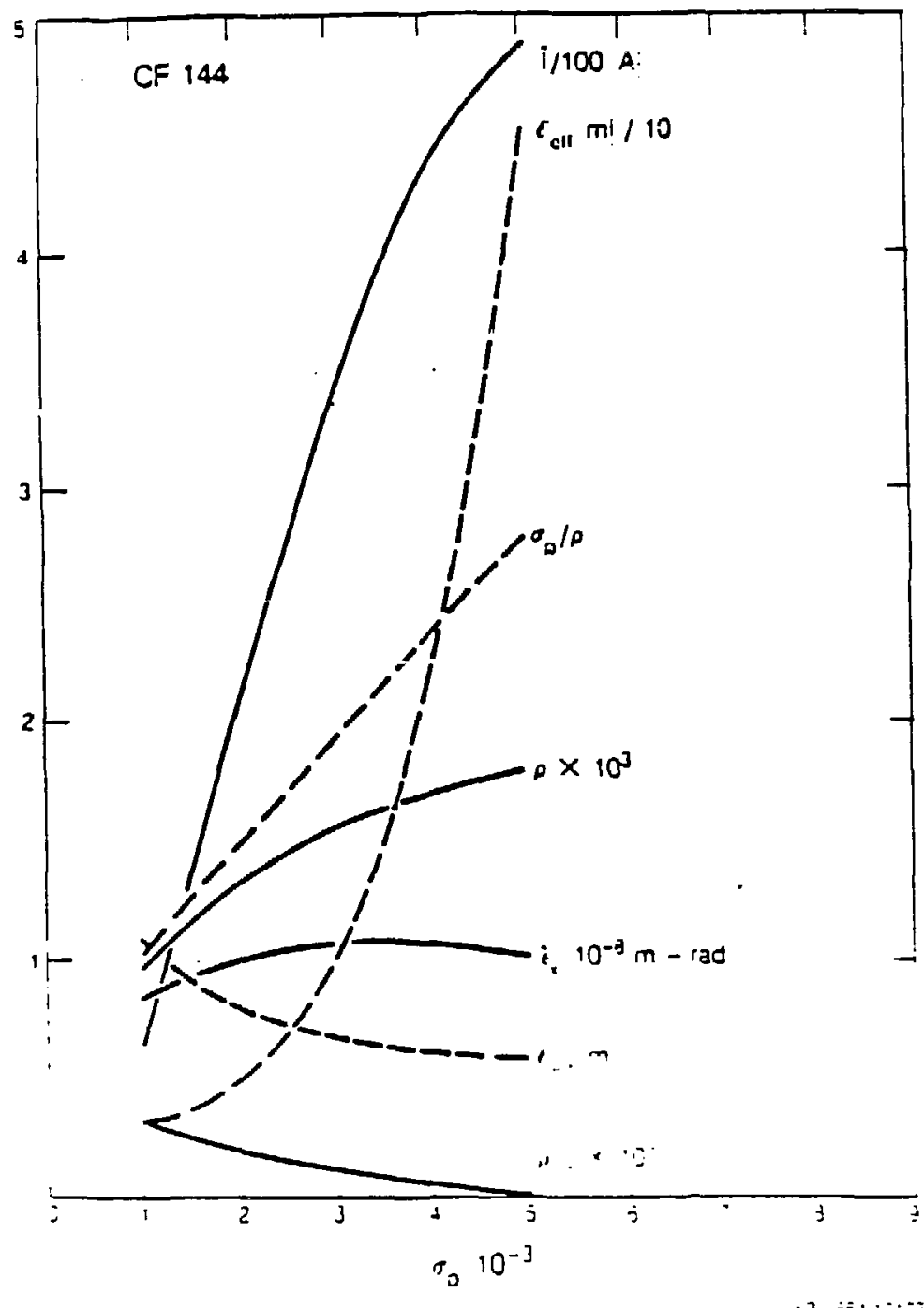

Flg. 2 Dependence of the peak curcent, I, equ1librium emittance, $\bar{\varepsilon}_{x}$, and some FEL parameters ( $\rho, \ell_{e}$ ) on the momentum spread. $\sigma_{p}$. Degradation of performance ( $P$ eEF, 2eff) with increas ing momencum spread is apparent. A Lorentzian momentum distribution was assumed in the calcula. clon of the degcadacion [see Eqn. (2.17)]. 


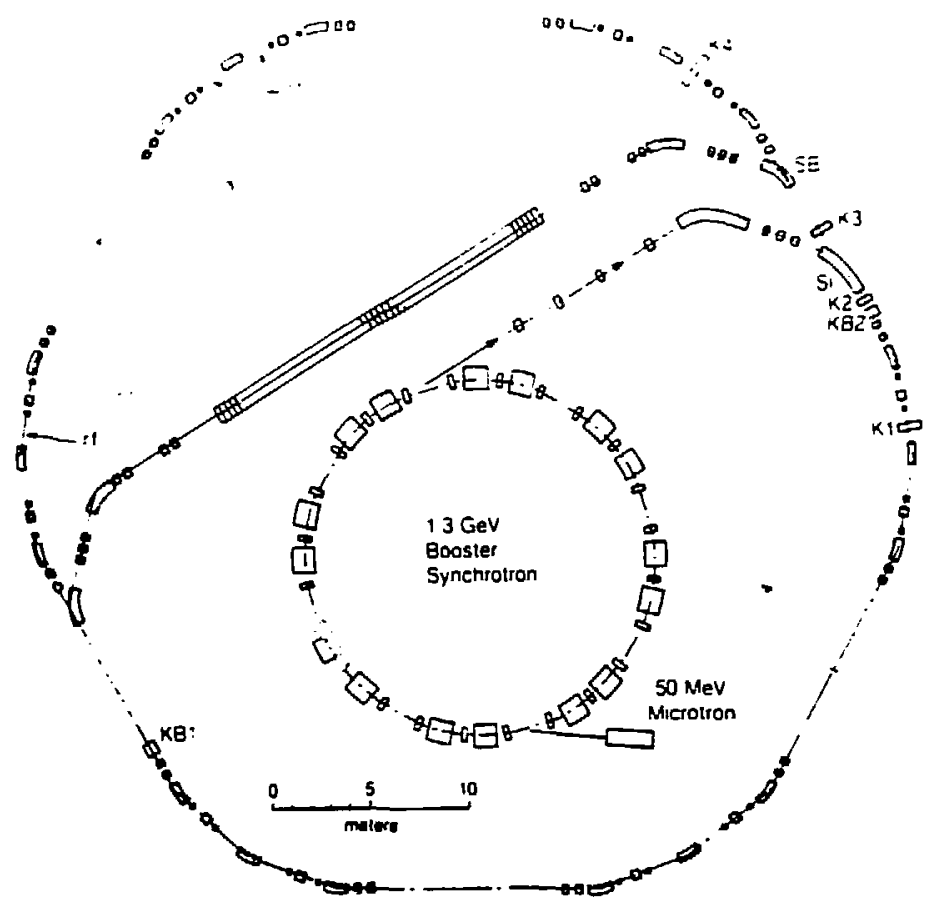

X8L $854-2286$

E1g. 3 Schematlc layout of IIng CE144 and bypass.

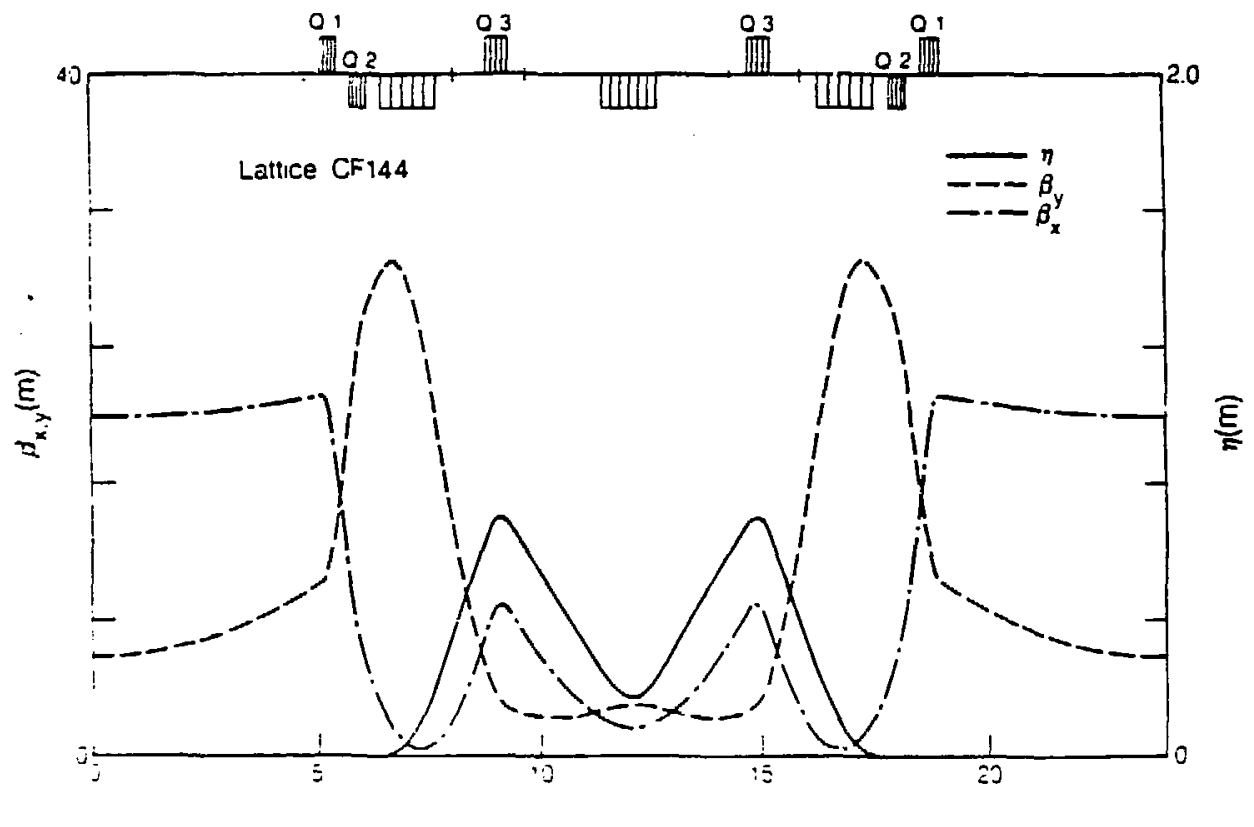

D.siance from Center $\sigma^{4}$ Lorg Straight Section (m)

Fig. 4 Lattice structure and functions in one period of lattice CF144. The pattern repeats six times around the ring. 


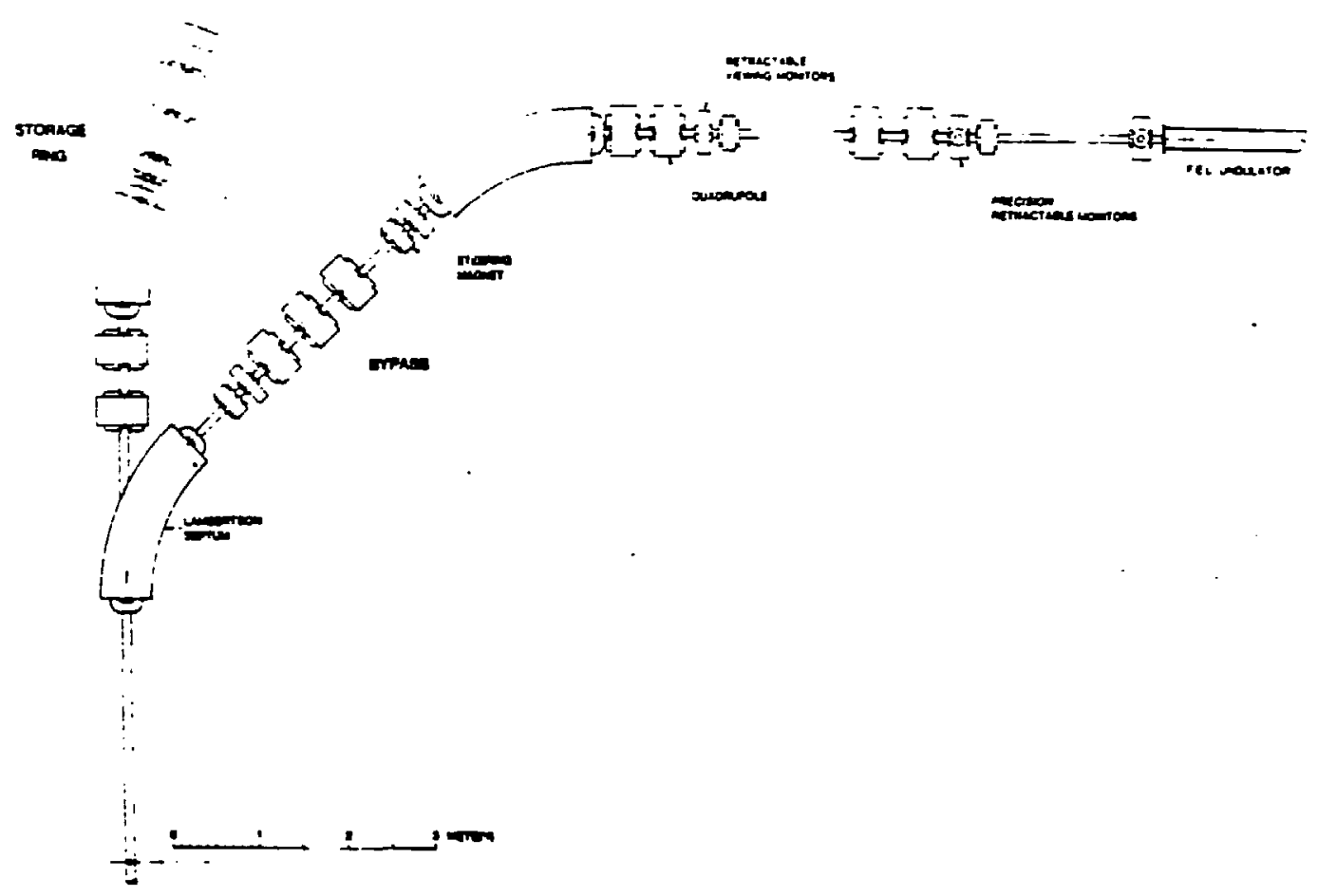

XBL 854-1996

Flg. 5 Layout of the transfer line to the EEL undulator.

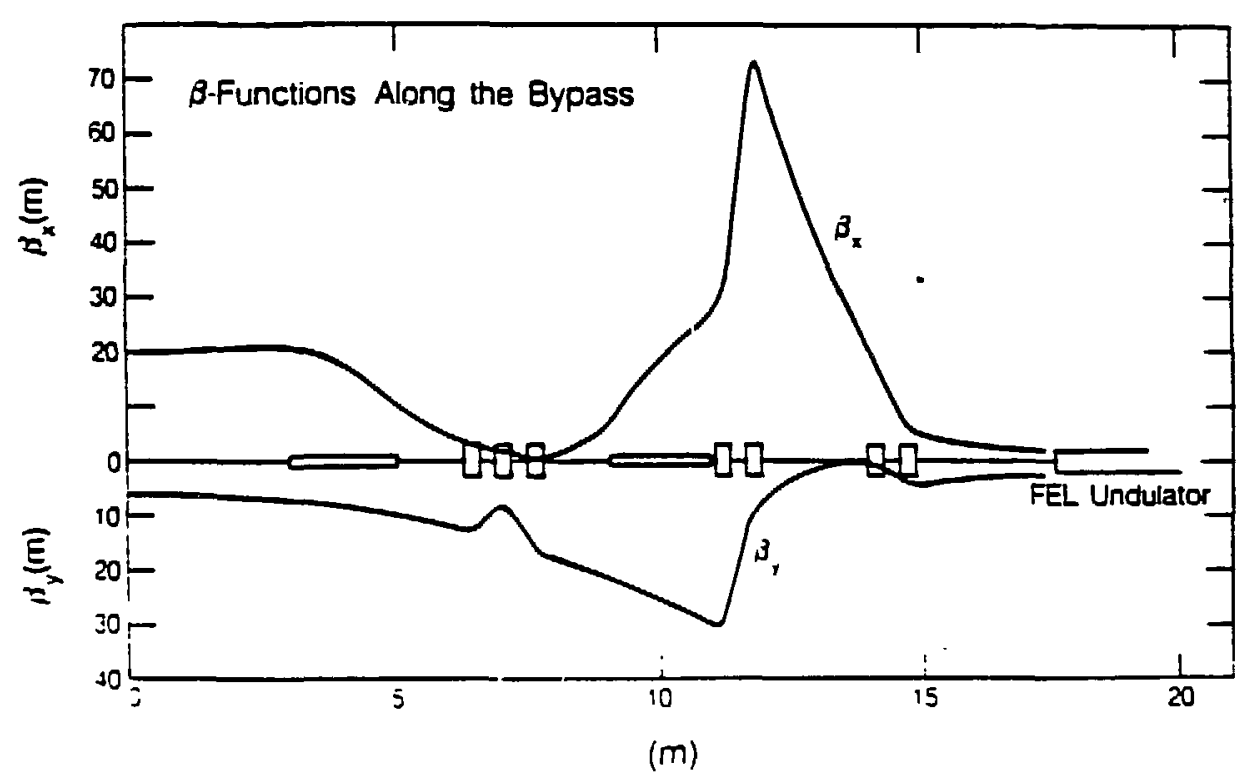

KBL 354-10163

E1g. 6 Evolution of the B-function in the bypass. 